\title{
Spatio-temporal variability of soil respiration in a spruce-dominated headwater catchment in western Germany
}

\author{
A. Y. Bossa and B. Diekkrüger \\ Department of Geography, University of Bonn, Meckenheimer Allee 166, 53115 Bonn, Germany \\ Correspondence to: A. Y. Bossa (baymar5@hotmail.com)
}

Received: 25 November 2013 - Published in Biogeosciences Discuss.: 13 January 2014

Revised: 24 June 2014 - Accepted: 3 July 2014 - Published: 12 August 2014

\begin{abstract}
CO}_{2}$ production and transport from forest floors is an important component of the carbon cycle and is closely related to the global atmosphere $\mathrm{CO}_{2}$ concentration. If we are to understand the feedback between soil processes and atmospheric $\mathrm{CO}_{2}$, we need to know more about the spatiotemporal variability of this soil respiration under different environmental conditions. In this study, long-term measurements were conducted in a spruce-dominated forest ecosystem in western Germany. Multivariate analysis-based similarities between different measurement sites led to the detection of site clusters along two $\mathrm{CO}_{2}$ emission axes: (1) mainly controlled by soil temperature and moisture condition, and (2) mainly controlled by root biomass and the forest floor litter. The combined effects of soil temperature and soil moisture were used as a time-dependent rating factor affecting the optimal $\mathrm{CO}_{2}$ production and transport at cluster level. $\mathrm{High} /$ moderate/weak time-dependent rating factors were associated with the different clusters. The process-based, most distant clusters were identified using specified pattern characteristics: the reaction rates in the soil layers, the activation energy for bio-chemical reactions, the soil moisture dependency parameter, the root biomass factor, the litter layer factor and the organic matter factor. A HYDRUS-1D model system was inversely used to compute soil hydraulic parameters from soil moisture measurements. Heat transport parameters were calibrated based on observed soil temperatures. The results were used to adjust $\mathrm{CO}_{2}$ productions by soil microorganisms and plant roots under optimal conditions for each cluster. Although the uncertainty associated with the HYDRUS-1D simulations is higher, the results were consistent with both the multivariate clustering and the timedependent rating of site production.
\end{abstract}

Finally, four clusters with significantly different environmental conditions (i.e. permanent high soil moisture condition, accumulated litter amount, high variability in soil moisture content, and dominant temperature dependence) were found to be relevant in explaining the spatio-temporal variability of $\mathrm{CO}_{2}$ efflux and providing reference-specific characteristic values for the investigated area.

\section{Introduction}

Understanding the feedback between terrestrial ecosystems and the atmosphere is one of the key issues for predicting the evolution of atmospheric $\mathrm{CO}_{2}$ concentration and global climatic change (Longdoz et al., 2000). Accordingly, more studies are required on the role of soil processes if we are to improve our understanding of the flux rate functions and the stability and resilience of soil processes that contribute to large-scale surface fluxes of water, heat and greenhouse gases (Fang and Moncrieff, 1999).

The release of $\mathrm{CO}_{2}$ from the soil surface is the result of a number of complex processes, including $\mathrm{CO}_{2}$ production, gas transport and interactions between physical and biological factors within the soil (Moncrieff and Fang, 1999). Carbon dioxide in the soil is produced by the oxidation of soil organic matter during litter decomposition by heterotrophic microorganisms and the respiration by plant roots (Jenkinson et al., 1991; Hui and Luo, 2004; Pandey et al., 2010; Jassal et al., 2005). Soil respiration is often measured as a flux of carbon dioxide from the soil surface, i.e. as soil $\mathrm{CO}_{2}$ efflux which approximately equals soil respiration at annual scale, but is influenced by transport conditions over shorter time steps (Raich and Schlesinger, 1992; Niinistö et al., 2011). 
Respiration is a suite of metabolic reactions regulated by two major abiotic factors, temperature and moisture, with soil temperature usually having an overriding influence in forest ecosystems (Schlesinger, 1977; Niinistö et al., 2011; Jassal et al., 2005). Soil $\mathrm{CO}_{2}$ transport to the atmosphere is controlled by the rate of $\mathrm{CO}_{2}$ production in the soil, the $\mathrm{CO}_{2}$ concentration gradient between the soil and the atmosphere, soil physical properties, and environmental conditions (diffusion through air-filled pores and cracks in the soil) (Raich and Schlesinger, 1992; Hui and Luo, 2004). The effects of soil temperature and soil moisture on $\mathrm{CO}_{2}$ effluxes are nonlinear and complex. A change in soil moisture has a greater impact when the temperatures are high, while a change in temperatures has a greater impact when the soil is humid (Howard and Howard, 1979; Joffre et al., 2003). Many previous studies (Fiener et al., 2011; Hashimoto et al., 2009; Niinistö et al., 2011; Shi et al., 2006) have based $\mathrm{CO}_{2}$ efflux estimation purely on soil temperature (using e.g. Arrhenius law) because soil moisture is found not to be a limiting factor in most of the studied regions. However, soil $\mathrm{CO}_{2}$ diffusivity changes with air-filled porosity, which in turn is affected by soil bulk density and soil water content (Jassal et al., 2005). This finding implies a potential link between changes in soil $\mathrm{CO}_{2}$ efflux and the soil moisture dependency parameter that characterizes a specific location. Richter et al. (1996) used a combination of the Arrhenius law and the Walker's empirical formula (Walker and Allen, 1984) to express temperature and moisture dependency through soil layers. This combination of laws could be used as a rating factor of soil $\mathrm{CO}_{2}$ efflux in regions where dependence on soil moisture is high.

Only a small number of studies have based a direct estimation of $\mathrm{CO}_{2}$ efflux on soil moisture content. For example, Xu and Qi (2001) applied soil moisture thresholds depending on site conditions to inter-seasonal $\mathrm{CO}_{2}$ efflux measurements to determine periods of high/weak temperature dependence and periods of positive/negative contributing effects of soil moisture. They used a nonlinear regression model, including soil temperature and moisture, and found explanations for 76 and $95 \%$ of the variation in soil $\mathrm{CO}_{2}$ efflux for soil volumetric moisture $<19 \%$ and $>19 \%$, respectively. However, although the results were good, they were forced to conclude that soil temperature and moisture are good predictors of the temporal variation of $\mathrm{CO}_{2}$ efflux but poor predictors of the spatial variations of soil $\mathrm{CO}_{2}$ efflux. In a study in a temperate forest Sitka spruce stand, Saiz et al. (2007) showed that soil temperature is the dominating factor, but soil moisture is more variable and had an overall negative effect on soil respiration.

By assuming that the influence of soil moisture and temperature was negligible, Fang et al. (1998) followed ideas developed by Sokal and Rohlf (1995) in which root and microbial respiration are considered as predictor variables when characterizing the spatial variability of $\mathrm{CO}_{2}$ efflux in a forest ecosystem in a Florida slash pine plantation. They developed a simple model to specify the spatial variation in $\mathrm{CO}_{2}$ efflux by further assuming that (1) live and dead biomass dominate the distribution of $\mathrm{CO}_{2}$ efflux on the forest floor and (2) microbial respiration in the mineral soil is inversely related to the amount of organic matter. Satisfactory results were obtained with the percentages of the variation in $\mathrm{CO}_{2}$ efflux accounted for by the variation in a predictor variable and associated variations in other variables. Thus 86, 64 and $36 \%$ of the variation was accounted for in the microbial respiration in the mineral soil, fine root respiration and the microbial respiration in the surface layer, respectively. These results suggest that such an approach may be extended by incorporating a time-dependent rating factor to account for regions where soil moisture is a limiting factor.

Accounting simultaneously for effects of bio-chemical reactions at a specific location and for time-dependent factors such as soil moisture and temperature is only possible with a relatively small number of process-based models (e.g. SOILCO2, PATCIS, HYDRUS-1D) (Fang and Moncrieff, 1999; Šimůnek et al., 2005; Šimůnek and Suarez, 1993a, b). In these models, $\mathrm{CO}_{2}$ production in the soil layers is related to the amount and quality of organic matter and to the live and dead root distribution through the soil layers. $\mathrm{CO}_{2}$ transport in the soil is linked to gas diffusion, liquid dispersion, gas convection and vertical water movement. The uncertainties associated with these models' results can be significantly reduced by inversely computing the model parameters from field measurements while minimizing the residual sum of squares. However, even if the models are able to predict $\mathrm{CO}_{2}$ dynamics relatively accurately, the large numbers of parameters to be calibrated, the poor data availability and the costs of experimental measurements mean that they are still weak models, but can be improved. Furthermore, the complexity of the models hampers the understanding of the processes and variables included in the model (Pumpanen et al., 2003). While applying HYDRUS-1D for the simulation of soil respiration in an agricultural field, Buchner et al. (2008) showed that HYDRUS-1D is well suited for modelling and that $\mathrm{CO}_{2}$ efflux strongly depends on soil hydrological properties which determine degradation as well as transport rates within the soil.

The spatio-temporal variability of soil respiration is analysed in a number of studies ranging from global to local scales. Reichstein et al. (2003) analysed 17 sites in Europe and North America with different site properties. Within the EUROFLUX project, Morales et al. (2005) applied different models for a number of sites spread over Europe to determine model applicability to this data set. From this study, not too much can be learned concerning the effect of site conditions on soil respiration. Kang et al. (2003) studied the effect of local topographic and climatic conditions on soil respiration in Korea. They compared six slopes with different aspect, elevation, and rainfall and found again that temperature is the most important driver. Pacific et al. (2009) investigated how large the effect of local-scale topography is on soil respiration. They analysed two different positions along a transect 
from the riparian zone of a river to the drier hill slope for two short periods (less than 3 months) in a wet and a dry year. They found a strong influence of the hill slope position on soil respiration which is further modified by climate conditions. Because the measurement periods were rather short and they did not attempt to model the data, the findings cannot be transferred directly to other sites.

This study involved measurements sites with both similar and significantly different topographic conditions. This procedure was chosen because it was assumed that different topographic conditions may result in different soil parameters with different moisture dynamics, but may not necessarily show comparable root biomass contents or litter depths, for instance. If this assumption proves viable, it indicates that a high level of complexity may exist and affect the specification of $\mathrm{CO}_{2}$ variability within the study area. Multivariate analyses, such as multiple factor analyses, may potentially provide linkages between environmental properties and $\mathrm{CO}_{2}$ efflux and account for similarities and dissimilarities between the investigated measurement sites.

The objective of this study is to analyse and understand the spatio-temporal variability of $\mathrm{CO}_{2}$ efflux patterns and their determining factors from measurement sites with significantly different environmental properties, qualified as specific sites. This objective is met by applying multivariate data analysis techniques to develop a simple nonlinear model describing a time-dependent rating of site-specific $\mathrm{CO}_{2}$ production and transport and comparing results with the output of the process-based HYDRUS-1D model system.

\section{Materials and methods}

\subsection{Site description}

The study was carried out in the Wüstebach catchment (38 ha in size, Fig. 1) located in the low mountain area of the Eifel National Park $\left(50^{\circ} 30^{\prime} \mathrm{N}, 6^{\circ} 19^{\prime} \mathrm{E}\right.$, WGS84), Germany. It is a spruce-dominated headwater catchment, a tributary of the Erkensruhr River in western Germany. The catchment has a warm temperate oceanic climate with a mean annual temperature of $7^{\circ} \mathrm{C}$, yearly mean sunshine from 1500 to $1600 \mathrm{~h}$ and a mean annual precipitation usually ranging from 1100 to $1200 \mathrm{~mm}$ (Sciuto and Diekkrüger, 2010). The altitude increases from $595 \mathrm{~m}$ in the north to $628 \mathrm{~m}$ in the south, while the mean slope is $3.6 \%$ with a maximum of $10.4 \%$ (Bogena et al., 2010; Rosenbaum et al., 2012). The bedrock consists of Devonian shales with sporadic sandstone inclusions and is covered by a $1-3 \mathrm{~m}$ thick periglacial solifluction layer in which mainly Cambisols in the western part and stagnic Cambisols in the eastern part of the site have developed (Rosenbaum et al., 2012). Gleysols, Stagnosols or Histosols are present in the groundwater-influenced floodplains alongside the Wüstebach stream, (Dwersteg, 2012). The catchment is densely forested by Norway spruce (Picea abies), a species characterized by a shallow root system; the plant coverage is about $90 \%$ (Sciuto and Diekkrüger, 2010).

\subsection{Measurements and data processing}

In this study, soil $\mathrm{CO}_{2}$ efflux was measured on a weekly basis using a closed dynamic chamber system (LI-8100, LiCor Inc., Lincoln, Nebraska, USA). The $\mathrm{CO}_{2}$ efflux from the soil was estimated by placing the chamber on PVC collars (20 cm diameter) and measuring the increase of $\mathrm{CO}_{2}$ within the chamber. The insertion depth of the collars was $5-8 \mathrm{~cm}$ into the forest floor. Along with soil $\mathrm{CO}_{2}$ efflux, the soil temperature and soil moisture were measured weekly and a soil survey analysis was conducted, including soil bulk density, root biomass, organic matter content and grain size distribution. Soil temperature was measured with a Testo 100 (Testo AG, Germany) temperature device at the depths of 5 and $11 \mathrm{~cm}$. Measurements in the depth of $11 \mathrm{~cm}$ were available for the whole measurement period, while soil temperature measurements in $5 \mathrm{~cm}$ depth were limited to the period 2008-2010. Dwersteg (2012) analysed the differences in correlation between 5 and $11 \mathrm{~cm}$ using an Arrhenius relationship. She found that the coefficient of determination slightly reduces from 0.9 to 0.85 when data are used from $11 \mathrm{~cm}$ depth instead of $5 \mathrm{~cm}$. Because of the variability in the thickness of the litter layer, Dwersteg decided to use $11 \mathrm{~cm}$ depth in order to always be in the mineral soil. This is similar to the approach of Saiz et al. (2007) who compared soil temperature measurements in 2 and $10 \mathrm{~cm}$ soil. Soil moisture was measured with a TDR soil moisture probe (TrimeFM soil moisture probe, IMKO, Germany) over an interval of $15 \mathrm{~cm}$ (including soil litter). A total of 80 single points along two different transects across the investigated catchment river and at a grid set-up in the southern part of the catchment were monitored from 2006 to 2012 (cf. Dwersteg, 2012 for more details). In the present study, our objective is to analyse how the heterogeneity of the catchment is affecting the $\mathrm{CO}_{2}$ pattern, so 10 measurements sites were selected according to different site properties. To confirm the selection process, the measurements of the 10 selected sites were grouped using a cluster analysis to show consistencies with the selection criteria, such as topography, soil type and proximity to the river. It should be noted that in our approach a high number of clusters is expected.

As reported by Dwersteg (2012), each measurement point was sampled for bulk density in $10 \mathrm{~cm}$ depth and bulk density of the litter layer using metal cylinders ( $8 \mathrm{~cm}$ diameter), and detailed soil profiles for bulk density were generated for each soil type (in total eight profiles) using soil core sampling. The organic matter content and root biomass were determined through six soil profiles representing six different soil types. The organic matter content in the soil or litter was determined using a Carbon/Nitrogen/Sulphur analyser (CNS2000, Leco, St. Joseph, Michigan, USA). Soil bulk density was determined by retrieving undisturbed cores of known 


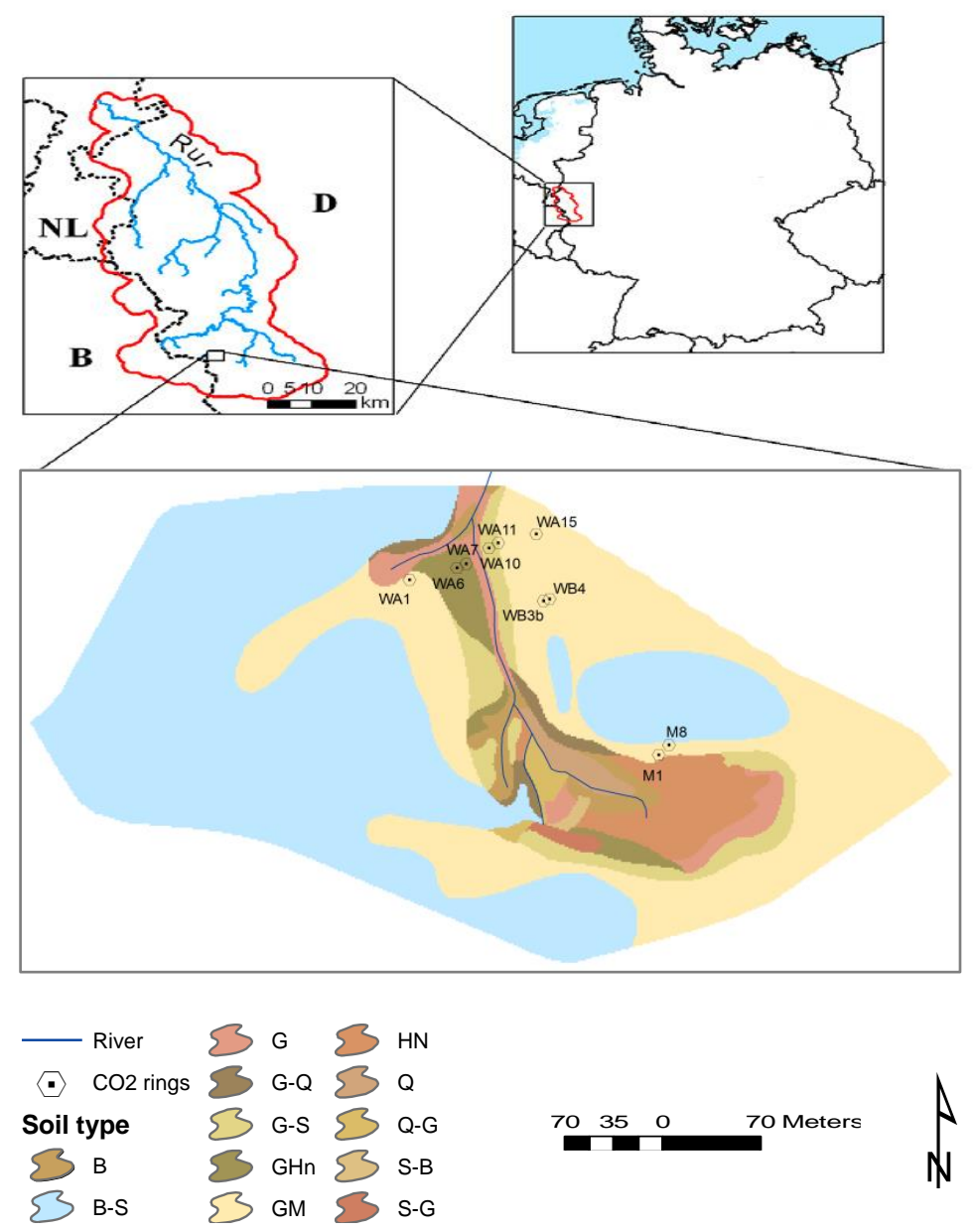

\begin{tabular}{lccccccc}
\hline Site & Soil type & $\begin{array}{c}\text { Slope } \\
(\%)\end{array}$ & $\begin{array}{c}\text { Elevation } \\
(\mathrm{m})\end{array}$ & $\begin{array}{c}\text { Bulk density } \\
{\left[\mathrm{g} \mathrm{cm}^{-3}\right]}\end{array}$ & $\begin{array}{c}\text { Root biomass } \\
{\left[\mathrm{g} \mathrm{m}^{-2}\right]}\end{array}$ & $\begin{array}{c}\text { Organic matter } \\
{\left[\mathrm{g} \mathrm{m}^{-2}\right]}\end{array}$ & $\begin{array}{c}\text { Litter thickness } \\
{[\mathrm{m}]}\end{array}$ \\
\hline WA1 & S-B: Gleyic Cambisol & 8.84 & 600 & 0.82 & 131.25 & 10029.67 & 0.02 \\
WA6 & S-G: Stagnic Eutric Gleysol & 5.59 & 598 & 0.91 & 73.20 & 12272.50 & 0.02 \\
WA7 & S-G: Stagnic Eutric Gleysol & 5 & 598 & 0.90 & 73.20 & 12272.50 & 0.02 \\
WA10 & B-S: Cambisol & 5.3 & 597 & 0.67 & 177.73 & 10029.67 & 0.04 \\
WA11 & B-S: Cambisol & 7.29 & 598 & 0.70 & 177.73 & 10029.67 & 0.02 \\
WA15 & S-B: Gleyic Cambisol & 12.87 & 601 & 0.70 & 131.25 & 10029.67 & 0.02 \\
WB3 & S-B: Gleyic Cambisol & 12.75 & 604 & 0.82 & 131.25 & 12511.83 & 0.03 \\
WB4 & S-B: Gleyic Cambisol & 14.25 & 605 & 0.76 & 131.25 & 12511.83 & 0.02 \\
M1 & S-B: Gleyic Cambisol & 7.29 & 616 & 0.76 & 28.58 & 11019.17 & 0.04 \\
M8 & S-B: Gleyic Cambisol & 7.29 & 617 & 0.84 & 52.40 & 7330.17 & 0.08 \\
\hline
\end{tabular}

Figure 1. Location of the measurement sites (M1, M8, WA1, WA6, WA7, WA10, WA11, WA15, WB3b, WB4) in the Wüstebach catchment, Germany, as used in this study (modified from Sciuto and Diekkrüger, 2010).

volume to subsequently oven-dry the samples at $105^{\circ} \mathrm{C}$ until a constant weight was reached. Samples for determining root biomass were rinsed and sieved to detach roots from soil mineral particles. The washed root mass was then determined by classifying it into diameter classes and weighing it after being oven-dried at $70^{\circ} \mathrm{C}$ for $48 \mathrm{~h}$. The grain size distribution was analysed according to Köhn (ISO 11277 ) and by using a particle analyser (Analysette 22, Fritsch, Germany). Soil information for the model was taken from a soil map $(1: 5000$; Fig. 1) produced by the Geologischer Dienst NRW and from literature (AG Bodenkunde, 2005). 


\subsection{Time-dependent rating of site-specific $\mathrm{CO}_{2}$ efflux}

The combined effects of soil temperature and soil moisture were used as a time-dependent rating factor affecting a sitespecific optimal $\mathrm{CO}_{2}$ production and transport. This method is a generalized estimation approach to characterize $\mathrm{CO}_{2}$ efflux within the catchment. In the method, observed soil temperature, soil moisture, soil parameters and soil $\mathrm{CO}_{2}$ efflux are used to automatically solve a generalized equation where only site-specific $\mathrm{CO}_{2}$ production and transport parameters are unknown. The classical law of Arrhenius, the empirical formula of Walker and Allen (1984), and a formula characterizing a site-specific $\mathrm{CO}_{2}$ efflux developed by Fang et al. (1998) are combined to account for the temporal pattern of soil $\mathrm{CO}_{2}$ efflux. An Excel solver engine was used to find optimal parameter values based on the Generalized Reduced Gradient Nonlinear approach.

According to Fang et al. (1998), a site-specific $\mathrm{CO}_{2}$ efflux from the soil surface at a certain time $t$ and in a forest environment can be expressed as a sum of root and microbial respiration:

$F^{*}=R_{\mathrm{r}}+R_{\mathrm{ml}}+R_{\mathrm{ms}}$,

where $F^{*}$ is the $\mathrm{CO}_{2}$ efflux from the soil surface and $R_{\mathrm{r}}, R_{\mathrm{ml}}$, and $R_{\mathrm{ms}}$ are root respiration, microbial respiration in litter and humus layers and microbial respiration in the mineral soil, respectively. $F^{*}$ is finally expressed as

$F^{*}=a+b B \phi+c M_{1}-d \ln \left(M_{\mathrm{s}}\right) / \phi$,

where $B$ is the biomass of live fine roots in the soil, $\phi$ is the soil total porosity, $M_{1}$ is the present amount of litter and humus of forest floor, $M_{\mathrm{S}}$ is the amount of organic matter in the mineral soil at time $t$ and $a, b, c$ and $d$ are parameters to be determined in agreement to the observations. $\ln$ is the logarithmic function with base $e$. It is assumed that soil parameters do not change within the short time of the investigations.

Richter et al. (1996) mentioned that under field conditions soil temperature $(T)$ and soil humidity $(\theta)$ act simultaneously as a kinetic parameter $K$ (Eq. 3), affecting the degradation rate of pesticide through soil layers. The approach used in this work assumed the same effect but as a rating factor on the optimal $\mathrm{CO}_{2}$ production/transport at a specific location. Thus $\mathrm{CO}_{2}$ efflux at a specific location over time, $F$ (Eq. 4), can be expressed as the product of $F *$ (Fang et al., 1998) by $K$ (Richter et al., 1996).

$K(\theta, T)=K(\theta) K(T)=A \theta^{\alpha} k_{0} e^{\frac{-\Delta E}{R T}}$,

where $K(\theta)$ is the empirical formula of Walker and Allen (1984), $K(T)$ is the classical law of Arrhenius, $k_{0}$ is the reaction rate at reference temperature $T_{0}\left(\mathrm{~T}^{-1}\right), \Delta E$ is the activation energy $\left(\mathrm{J} \mathrm{mol}^{-1}\right), \alpha$ is the parameter describing soil moisture dependency $\left(T^{-1}\right)$, A is the humidity response function parameter set equal to 1 in the following steps as in Richter et al. (1996), and $R$ is the gas constant $\left(\mathrm{kJ}(\mathrm{mol} \mathrm{K})^{-1}\right)$.

$F=F^{*} K(\theta, T)=(a+b B \phi+c M l-d \ln (M s) / \phi) \theta^{\alpha} k_{0} e^{\frac{-\Delta E}{R T}}$

where $a, b, c, d, k_{0}, \Delta E$ and $\alpha$ are parameters to be determined in agreement to the measurements (soil temperature, soil moisture, $\mathrm{CO}_{2}$ efflux and soil parameters).

\subsection{HYDRUS-1D parameterization}

HYDRUS-1D (Šimůnek et al., 2005) is a one-dimensional process-based model used in this study to simulate daily soil $\mathrm{CO}_{2}$ efflux. HYDRUS-1D incorporates simulation components such as water flow, heat transport and the movement of solutes considering first-order decay reactions in variably saturated soils. HYDRUS-1D uses the Richards equation (Eq. 5) for simulating variably saturated flow and the Fickian-based advection-dispersion equations for heat and solute transport. The water flow equation incorporates a sink term to account for water uptake by plant roots. The heat transport equation considers transport due to conduction and convection with flowing water.

$\frac{\partial \theta}{\partial t}=\frac{\partial}{\partial x}\left[K\left(\frac{\partial h}{\partial x}+\cos \beta\right)\right]-S$,

where $h$ is the water pressure head (L), $\theta$ is the volumetric water content $\left(\mathrm{L}^{3} \mathrm{~L}^{-3}\right), t$ is the time $(T), x$ is the spatial coordinate (L) (positive upward), $S$ is the sink term $\left(\mathrm{L}^{3} \mathrm{~L}^{-3} \mathrm{~T}^{-1}\right)$, $\beta$ is the angle between the flow direction and the vertical axis (i.e. $\beta=0^{\circ}$ for vertical flow, $90^{\circ}$ for horizontal flow, and $0^{\circ}<\beta<90^{\circ}$ for inclined flow), and $K$ is the unsaturated hydraulic conductivity function $\left(\mathrm{L} \mathrm{T}^{-1}\right)$. The sink term, $S$, is defined as the volume of water removed from a unit volume of soil per unit time due to plant water uptake as described by Feddes et al. (1978).

HYDRUS-1D assumes that the individual $\mathrm{CO}_{2}$ production processes are additive and performs the calculation as the superposition of individual processes that reduce production from the optimal value (Šimůnek and Suarez, 1993a). Thus, the production of $\mathrm{CO}_{2}$ is considered as the sum of the production by soil microorganisms and by plant roots. HYDRUS-1D also assumes that the $\mathrm{CO}_{2}$ transport in the unsaturated zone can occur in both the liquid and gas phases. Furthermore it is assumed that the $\mathrm{CO}_{2}$ concentration in the soil is governed by two transport processes: convective and diffusive transport in both gas and aqueous phases, and $\mathrm{CO}_{2}$ production and/or removal (Patwardhan et al., 1988).

In this study, the atmospheric boundary condition at the surface layer (i.e. daily potential evaporation and transpiration fluxes, daily rainfall, and daily air temperature) is used for the upper water flow boundary condition. This condition permits water to build up on the surface. The height of the surface water layer increases due to precipitation and is reduced because of infiltration and evaporation. The lower water flow boundary condition is set to constant pressure head. 
The upper heat transport boundary condition is set to temperature boundary condition, and the lower heat transport boundary condition is set to zero gradient. The snow melting constant, the amount of snow that will melt during 1 day for each ${ }^{\circ} \mathrm{C}$, is set to $0.43 \mathrm{~cm}$ while the sublimation constant used to reduce the potential evaporation from an existing snow layer is set to 0.4 .

\subsection{Inverse simulation approach}

Hydraulic parameters behind the $\mathrm{CO}_{2}$ simulations were estimated and optimized from the soil moisture measurements using an inverse modelling approach included in HYDRUS1D. The objective function $\varphi$ (Eq. 6) minimized during the parameter estimation process is described by Simunek et al. (1998). The first term represents deviations between the measured and calculated space-time variables (water contents at different locations and/or time in the flow domain). The second term represents differences between independently measured and predicted soil hydraulic properties (e.g. retention, hydraulic conductivity). The last term represents a penalty function for deviations between prior knowledge of the soil hydraulic parameters and their final estimates.

$$
\begin{aligned}
\varphi(b, q, p) & =\sum_{j=1}^{m_{q}} v_{j} \sum_{i=1}^{n_{q i}} w_{i, j}\left[q_{j}^{*}\left(x, t_{i}\right)-q_{j}\left(x, t_{i}, b\right)\right]^{2} \\
& +\sum_{j=1}^{m_{p}} v_{j} \sum_{i=1}^{n_{p i}} w_{i, j}\left[p_{j}^{*}\left(\varepsilon_{i}\right)-p_{j}(\varepsilon, b)\right]^{2} \\
& +\sum_{j=1}^{n_{b}} v_{j}\left[b_{j}^{*}-b_{j}\right]^{2}
\end{aligned}
$$

where, $m_{q}$ and $m_{p}$ are the number of different sets of measurements, $n_{q j}$ and $n_{p j}$ are the number of measurements in a particular measurement set, $q_{j}^{*}\left(x, t_{i}\right)$ and $p_{j}^{*}\left(\varepsilon_{i}\right)$ represent specific measurements at time $t_{i}$ for the $j$ th measurement set at location $x, q_{j}\left(x, t_{i}, b\right)$ and $p_{j}\left(\varepsilon_{i}, b\right)$ are the corresponding model predictions for the vector of optimized parameters $b$ (e.g. $\theta_{r}, \theta_{s}, a, n$, and $K_{s}$, van Genuchten parameters), and $v_{j}$ and $w_{i, j}$ are weights associated with a particular measurement set or point, respectively.

\subsection{Uncertainty approach}

A new processing and executing routine was developed (using a FORTRAN environment) for the HYDRUS-1D model allowing the user to run hundreds of simulations at once based on a very large parameter matrix that can be obtained by e.g. Latin Hypercube sampling (McKay et al., 1979). The quality measure of the model performance (fitting to the measurements) is evaluated by the coefficient of determination $R^{2}$, the model efficiency (ME) of Nash and Sutcliffe (1970) and the index of agreement of Willmott (1981). The coefficient of determination $R^{2}$ describes the linear dependency between measured and simulated values within the range of 0 to 1 . The ME describes the degree of accordance between observed and simulated values and varies between $-\infty$ and 1 .
The index of agreement ranging between 0 and 1 is strongly influenced by the mean value (simulated or observed variable) and evaluates the performance of the temporal characteristics of the simulated curves. A value of 1 indicates a complete agreement between measured and simulated values.

The initial model parameter sets considered in the uncertainty analysis are (1) optimized parameter sets $(a, b, c, d$, $\alpha, k_{0}$ and $\Delta E$ ) obtained by applying the Excel solver engine with the Generalized Reduced Gradient Nonlinear approach, (2) inversely computed hydraulic parameters using the HYDRUS-1D model and based on measured soil moisture, and (3) adjusted heat parameters, optimal $\mathrm{CO}_{2}$ production and transport parameters using HYDRUS-1D and based on measured temperature and $\mathrm{CO}_{2}$ efflux. To quantify the prediction uncertainties, an uncertainty of $\pm 1 \%$ was assumed for each parameter, thus generating parameter ranges for the Latin Hypercube sampling. The uncertainties in the predictions are quantified by the percentage of measurements bracketed by the $95 \%$ prediction uncertainty band ( $P$ factor) (Abbaspour et al., 2004). The 95\% uncertainty prediction is calculated at the 2.5 and $97.5 \%$ levels of cumulative distribution of an output variable obtained through e.g. Latin Hypercube sampling, excluding $5 \%$ of the very bad simulations (due to very bad parameter combination). The ratio of average distance between 2.5 and 97.5 percentiles of the cumulative distribution of the simulated variable and the standard deviation of the corresponding measured variable ( $R$ factor) provided insights into the thickness of the uncertainty band (Abbaspour et al., 2004).

\section{Results and discussion}

\subsection{Multivariate dependence of $\mathrm{CO}_{2}$ efflux}

The measurements ( $n=984$ observations) analysed in this work are from 10 sites characterized by significantly different slope values ranging from 3.6 to $10.4 \%$. In some cases, the sites are very close to the river bed, e.g. sites WA6 and WA7 (cf. Fig. 1). Here, lateral flow may differently influence site-specific soil moisture and thus greatly affect the $\mathrm{CO}_{2}$ efflux from soil. Table 1 shows descriptive statistics of all measured variables at the different sites. The soil parameters are presented as mean values for the entire soil profiles. This table shows that the litter depth and the density of root biomass displayed the highest coefficients of variation and may be relevant factors for characterizing a sitespecific behaviour. Nevertheless, this result should also be analysed with caution, since randomly distributed observations are obtained for the density of root biomass and not for the litter depth (Table 1). Thus, all investigated soil parameters are randomly distributed except the litter depth, which may be highly influenced by local-scale factors, such as wind or transport through preferential surface flow. 
Table 1. Descriptive statistics ( $\mathrm{n}=984$ observations) for 10 sites (M1, M8, WA1, WA6, WA7, WA10, WA11, WA15, WB3, WB4) from 2006 to 2012 along two transects (cf. Fig. 1 for the locations of measurement sites and for more details). The symbol (-) means that the dynamic variables were not tested for normality.

\begin{tabular}{lrrrrrr}
\hline Variables & Min. & Max. & Mean & $\begin{array}{r}\text { Std. } \\
\text { deviation }\end{array}$ & $\begin{array}{r}\text { Coef. of } \\
\text { variation }\end{array}$ & $\begin{array}{r}\text { Normally } \\
\text { distributed }\end{array}$ \\
\hline Litter thickness $(\mathrm{m})$ & 0.02 & 0.08 & 0.03 & 0.02 & 0.57 & no \\
Bulk density $\left(\mathrm{g} \mathrm{cm}^{-3}\right)$ & 0.67 & 0.91 & 0.79 & 0.08 & 0.10 & yes \\
Root biomass $\left(\mathrm{g} \mathrm{m}^{-3}\right)$ & 28.6 & 177.7 & 113.2 & 47.9 & 0.42 & yes \\
Organic matter $\left(\mathrm{g} \mathrm{m}^{-3}\right)$ & 7330.2 & 12511.8 & 10833.6 & 1513.0 & 0.14 & yes \\
Soil moisture at $\left.15 \mathrm{~cm} \mathrm{depth}(\% \mathrm{Vol} .)^{\circ}\right)$ & 2.03 & 54.77 & 22.78 & - & - & - \\
Soil temperature at $11{\mathrm{~cm} \mathrm{depth}\left({ }^{\circ} \mathrm{C}\right)}^{0.00}$ & 15.80 & 8.58 & - & - & - \\
$\mathrm{CO}_{2}$ efflux $\left(\mu \mathrm{mol} \mathrm{m}^{-2} \mathrm{~s}^{-1}\right)$ & 0.02 & 8.74 & 2.51 & - & - & - \\
\hline
\end{tabular}

Figure 2 shows $\mathrm{CO}_{2}$ efflux rates for the investigated sites with their dependence on soil temperature and soil moisture for seasonal means over the period 2011 to 2012. The circle sizes indicate the rate of $\mathrm{CO}_{2}$ efflux at a given site. The transition from spring to summer is expressed by an average increase of soil temperature of about $5{ }^{\circ} \mathrm{C}$ and an average decrease in soil moisture of about $5 \%$. A global view on the flux pattern at relatively fix temperature ranges (seasonal means) shows that emission rates decrease with increasing soil moisture. A clear dependence of the $\mathrm{CO}_{2}$ pattern on soil temperature (transition from spring to summer) is not necessarily shown, even if the humidity conditions are similar, which is likely for the sites WA6 and WA7 as they are close to the river bed (permanently wet). In addition, $\mathrm{CO}_{2}$ emission rates may increase (e.g. WA1) or decrease (e.g. WB3) with increasing temperature and decreasing soil moisture. With a clearly changed moisture condition from spring to summer, the $\mathrm{CO}_{2}$ efflux rate may also remain similar (e.g. M8). Thus, the $\mathrm{CO}_{2}$ efflux rate remained, for instance, almost unchanged at site M8, while soil moisture decreased and soil temperature increased, a condition that, in principle, should simply lead to an increase of the flux (Shibistova et al., 2002). This result led us to conclude that in such an ecosystem, $\mathrm{CO}_{2}$ efflux from soil may not be highly affected by temporal factors, but it may be affected by spatial factors. The other sites M1, WA10, WA11, WA15 and WB4 may be classified anywhere between or within the cases mentioned above. It is important to remember that the measurement sites involved in this study may have differences and similarities (strongly linked to environmental properties) that cannot be clearly shown from a description based only on soil temperature and soil moisture measurements.

In summary, site WA6 is characterized by very low $\mathrm{CO}_{2}$ efflux due to permanent moisture conditions, while both the high emission rate of the site M1 and the relatively constant emission rate of M8 still have to be clarified. Particular behaviours of the other sites, if existing, remain unclear.
Combining information from Fig. 2 and calculated mean efflux values, it can be seen that

1. a seasonal (spring) mean soil $\mathrm{CO}_{2}$ efflux ranging from 1.2 to $3 \mu \mathrm{mol} \mathrm{m}^{-2} \mathrm{~s}^{-1}$ was associated with a large range of seasonal mean volumetric soil moisture ranging from 12 to $33 \%$, while the mean soil temperature remains relatively close to $8^{\circ} \mathrm{C}$

2. a seasonal (summer) mean soil $\mathrm{CO}_{2}$ efflux ranging from 1.7 to $4.5 \mu \mathrm{mol} \mathrm{m}^{-2} \mathrm{~s}^{-1}$ was associated with a large range of seasonal mean volumetric soil moisture ranging from 8 to $30 \%$, while the mean soil temperature remains relatively close to $12{ }^{\circ} \mathrm{C}$.

Both environmental factors and seasonal means of observed variables (e.g. $\mathrm{CO}_{2}$ efflux, soil moisture and soil temperature) from 2011 to 2012 were combined as multivariate data for a multiple factor analysis. In Fig. 3, the results show two main axes (factors F1 and F2) controlling about $70 \%$ of the total observed variance. $\mathrm{CO}_{2}$ significantly contributed to both axes at about $20 \%$ but at a higher rate for the axis F1. The factor F1 is mainly controlled by soil moisture and soil temperature, with a predominant influence of temperature in spring and a predominant influence of soil moisture in summer. $\mathrm{CO}_{2}$ efflux is positively correlated with soil temperature and negatively correlated with soil moisture. The factor F2 is mainly controlled by the litter depth and the root biomass, and this result seems to be consistent with the information previously drawn from Table $1 . \mathrm{CO}_{2}$ efflux is positively correlated with the root biomass and negatively correlated with the litter depth. Similarities between the sites are shown in the same axis system on the right side of the graphics (multivariate clustering). The arrows of the axes indicate emission gradients with M1 (cluster C1, Table 2) pointed out as the most important emission site. M1 is mainly dependent on soil temperature and should benefit from the transition from spring to summer, but this benefit is not clearly shown in Fig. 2, maybe due to adverse effects from soil moisture. The relatively constant and low emission rate at the site M8 results mainly from the litter depth. The figures show that if the 
Table 2. Potential clusters for characterizing the patterns of $\mathrm{CO}_{2}$ efflux in the study area.

\begin{tabular}{llllll}
\hline Cluster 1 (C1) & Cluster 2 (C2) & Cluster 3 (C3) & Cluster 4 (C4) & Cluster 5 (C5) & Cluster 6 (C6) \\
\hline M1 & M8 & WA1 & WA6 & WA10 & WA11 \\
& & WB3 & WA7 & WA15 & \\
& & & WB4 & \\
\hline
\end{tabular}
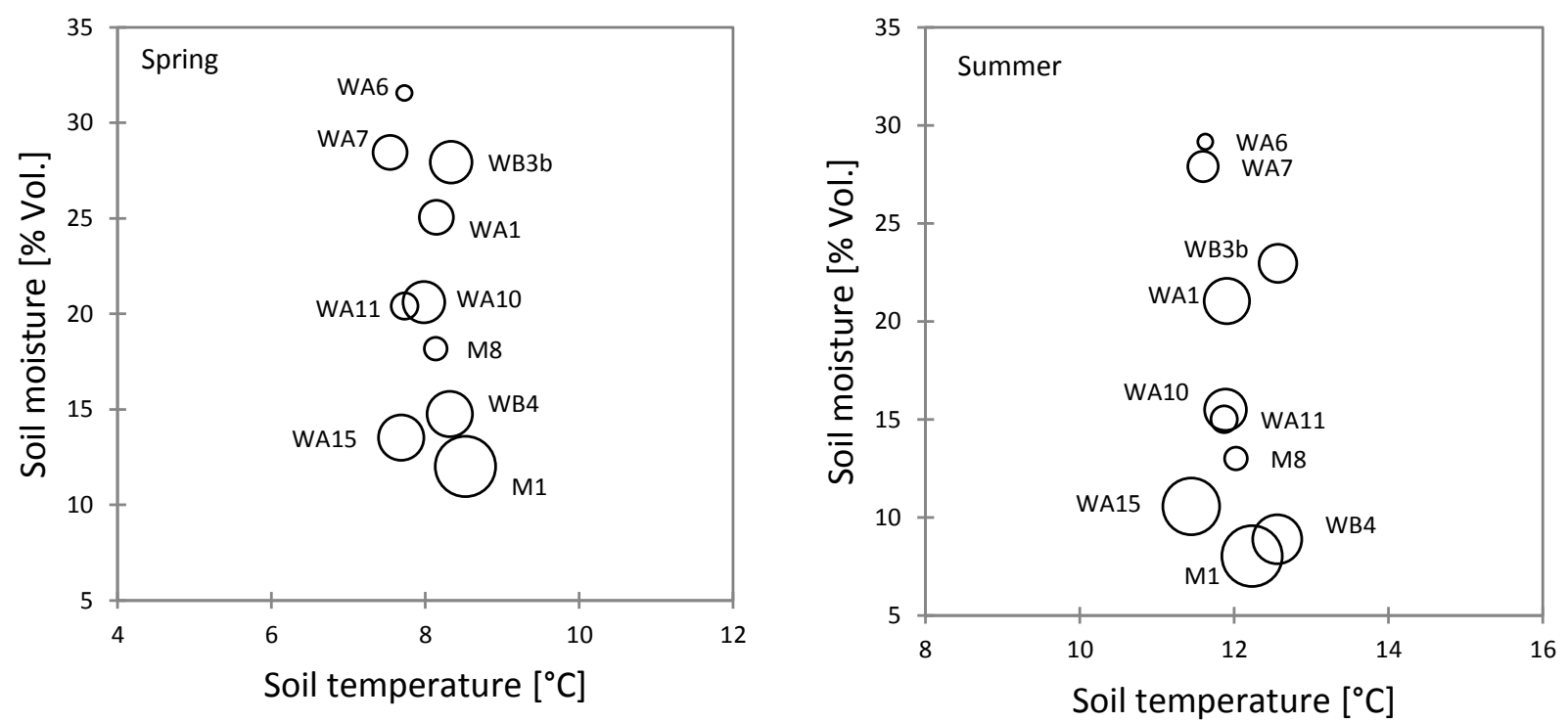

Figure 2. 2-D plot of $\mathrm{CO}_{2}$ efflux dependency on soil temperature and soil moisture and likely clustering based on average values observed from 2011 to 2012. The circle sizes indicate the rate of $\mathrm{CO}_{2}$ efflux at a given site.

litter is a factor that indirectly and positively influences the $\mathrm{CO}_{2}$ efflux through microorganism respiration, it could be at the same time a factor that regulates the emission rate (negative correlation between the litter depth and $\mathrm{CO}_{2}$ efflux). The site WA11 is mainly controlled by the root biomass. The sites WA10, WA15 and WB4 gathered in Cluster 5 (Fig. 3 and Table 2) are subjected to the simultaneous effects of the both factors F1 and F2.

One may conclude that the clusters $\mathrm{C} 1$ and $\mathrm{C} 5$ contain sites highly affected by the time-dependence rating factors, clusters C3 and C6 contain sites moderately affected by the time-dependence rating factor, and clusters $\mathrm{C} 2$ and $\mathrm{C} 4$ contain sites weakly affected by the time-dependence rating factor. Clusters C2, C4 and C5 are the most geometrically distant in reference to the Fig. 3 and should lead to significantly different site-specific parameters shown in Eq. (4) (e.g. reaction rate at reference temperature, activation energy, parameter describing soil moisture dependency, cluster constants).

\subsection{Site cluster weighting and characterization}

Figure 4 shows the estimated and observed soil $\mathrm{CO}_{2}$ efflux and the quality measure displayed in the bottom table. As mentioned in Sect. 2, the estimations are based on a nonlinear time-dependent rating of site-specific models (Eq. 4).
The estimation quality remains on average with coefficients of determination ranging from 0.43 to 0.65 , model efficiencies from 0.36 to 0.51 , and indices of agreement from 0.73 to 0.82 . Uncertainty quality measures are relatively high, with more than $50 \%$ of the measurements captured by the $95 \%$ prediction band, ranging from 53 to $60 \%$. The $R$ factor ranges between 0.53 and 1.09. The uncertainty analysis is based on optimized parameter sets obtained by applying the Excel solver engine with the Generalized Reduced Gradient Nonlinear approach. Afterwards an uncertainty of $\pm 1 \%$ was assumed for each parameter, thus generating parameter ranges that quantified the prediction uncertainty.

The estimated site-specific parameters are shown in Table 3. This table shows the large dissimilarities between clusters C2, C4 and C5/C6, compared to the others. These results are consistent with the multiple factor analysis discussed in the Sect. 3.1, in which clusters C2, C4 and C5 were found as the most distant (emission rate as well as predominance of factors). This result clearly shows how well seasonal mean information matches the weekly scale information since the multivariate analyses are performed using seasonal average data, while the parameter estimations are based on the weekly scale data. 
Table 3. Factor parameters obtained for the different clusters (cf. Eq. 4). $k_{0}=$ reaction rate at reference temperature $T_{0}\left(\mathrm{~T}^{-1}\right.$ ), $\Delta E=$ activation energy $\left(\mathrm{J} \mathrm{mol}^{-1}\right), \alpha=$ parameter describing soil moisture dependency $\left(\mathrm{T}^{-1}\right), a=$ cluster constant, $b=$ root biomass factor, $c=$ litter layer factor, $d=$ organic matter factor.

\begin{tabular}{lrrrrrrr}
\hline & $k_{0}\left(10^{8}\right)$ & $\Delta E\left(10^{4}\right)$ & $\alpha\left(10^{-4}\right)$ & $a\left(10^{-2}\right)$ & $b\left(10^{-2}\right)$ & $c\left(10^{-2}\right)$ & $d\left(10^{-2}\right)$ \\
\hline Cluster 1 & 12.22 & 7.12 & -2.78 & 2443546.23 & 2978.67 & 30088896.19 & 471.59 \\
Cluster 2 & 316.17 & 9.00 & -3.09 & 39840964.13 & 10332.46 & 1551055746.34 & 0.10 \\
Cluster 3 & 11.12 & 6.78 & -2.74 & 432919.94 & 97620.17 & 0.10 & 627307.69 \\
Cluster 4 & 13.41 & 6.78 & 56.32 & 818192.95 & 0.10 & 0.10 & 0.00 \\
Cluster 5 & 8.16 & 7.09 & -2.63 & 640958.13 & 13557.46 & 26824424.54 & 7480.35 \\
Cluster 6 & 68.68 & 7.23 & -1.85 & 0.88 & 1583662.25 & 39.94 & 5289549.76 \\
\hline
\end{tabular}
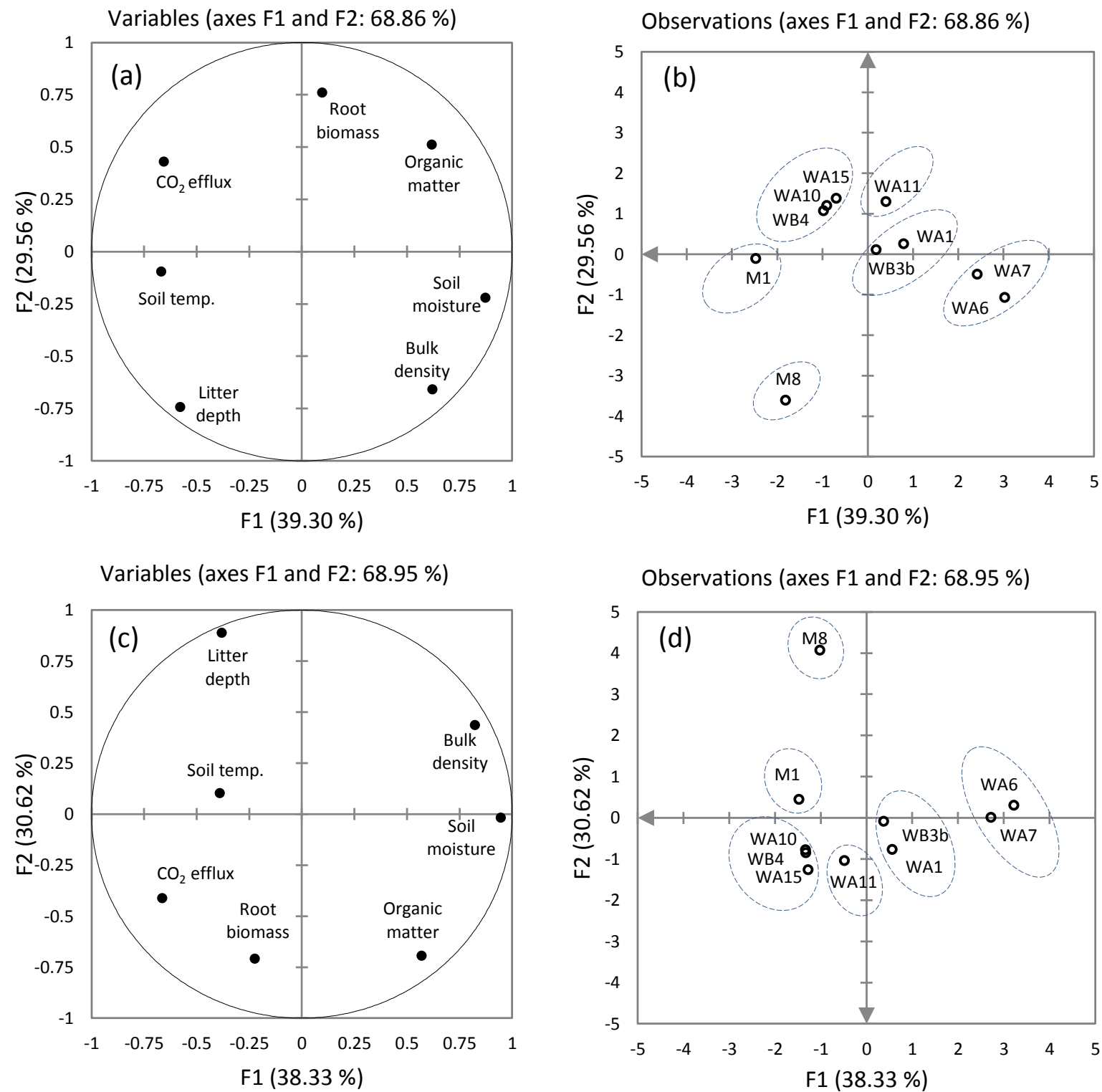

Figure 3. Multiple factor analysis (MFA) based on seasonal means of observed variables from 2011 to 2012. (a) and (c) are the correlations between variables and factors over spring and summer, respectively; (b) and (d) are the dependence of measurement sites on the factors and clustering over spring and summer, respectively. 

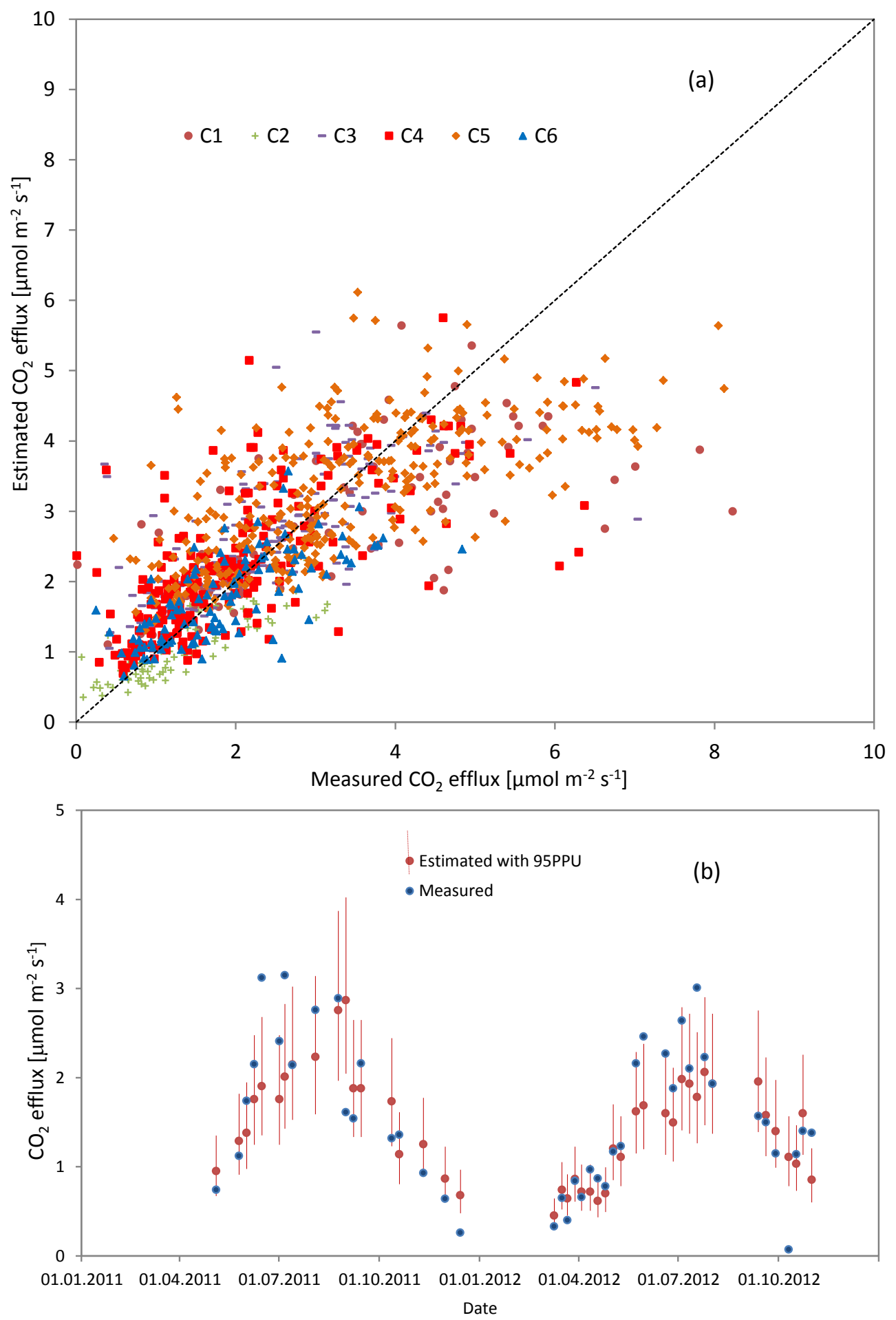

\begin{tabular}{lcccccc}
\hline & Cluster 1 & Cluster 2 & Cluster 3 & Cluster 4 & Cluster 5 & Cluster 6 \\
\hline Coef. D. & 0.43 & 0.65 & 0.52 & 0.47 & 0.47 & 0.49 \\
ME & 0.36 & 0.51 & 0.46 & 0.43 & 0.47 & 0.49 \\
IA & 0.73 & 0.81 & 0.82 & 0.80 & 0.77 & 0.80 \\
P-factor & 0.60 & 0.59 & 0.57 & 0.53 & 0.53 & 0.57 \\
R-factor & 0.91 & 1.03 & 0.53 & 1.01 & 1.07 & 1.09 \\
\hline
\end{tabular}

Figure 4. Estimated vs. observed $\mathrm{CO}_{2}$ efflux based on the time-dependent rating of site-specific production and transport approach (Eq. 4). (a) Scatter plot of simulated vs. measured $\mathrm{CO}_{2}$ efflux for all clusters from 2006 to 2012, (b) simulated vs. measured $\mathrm{CO}_{2}$ efflux with associated 95 percent prediction uncertainty (95PPU) from 2011 to 2012 for the site M8 (cluster C2). C1...6 means clusters 1 ...6. 
Combining information drawn from Fig. 4 and Table 3, it appears that clusters $\mathrm{C} 1, \mathrm{C} 2, \mathrm{C} 4$ and $\mathrm{C} 5$ may be seen as representative when characterizing the spatio-temporal pattern of $\mathrm{CO}_{2}$ efflux from the forest floor of the Wüstebach catchment:

1. Cluster C1 was clearly linked to the high temperaturedependent effects as derived from Fig. 3 and does not display any clear characteristic values in Table 3.

2. As previously found, Cluster $\mathrm{C} 2$ is minimally affected by the time-dependent rating factor but highly influenced by the combined effects of root biomass and litter depth. The effects of the litter depth are predominant and expressed as an inhibiting factor for $\mathrm{CO}_{2}$ production and transport. This result clearly explains the very high reaction rate at a reference temperature and the very high activation energy observed in Table 3 . As discussed in Sect. 3.1, if the litter is a factor indirectly and positively influencing the $\mathrm{CO}_{2}$ efflux through microorganism respiration, it could be at the same time a factor that regulates the emission rate, depending on how important and dense it is (resulting in a negative correlation between the litter depth and $\mathrm{CO}_{2}$ efflux). As already mentioned, different depths of litter may lead, for instance, to different velocities of heat transport or air diffusion from or into the soil layers. The problem raised here is then related to the quality of the forest floor litter and the organic matter, which may be affected by wind action, preferential runoff transport or deposition from different species as already pointed out by Longdoz et al. (2000).

3. Cluster $\mathrm{C} 4$ was found to be minimally influenced by both the time-dependent rating factor and a permanent moisture condition. These influences result in a moderate reaction rate at reference temperature and a very specific value as for the parameter describing soil water dependency (Table 3).

4. Clusters C5 and C6 are highly influenced by the combined effects of the time-dependent rating factor and the root biomass. This result is explained by the low value obtained for the parameter describing soil moisture dependency and the specific value obtained for the cluster constant (Table 3).

Many studies have investigated the litter control on soil respiration. Li et al. (2004) studied the effects of litter exclusion (exclusion of new litterfall over a 7-year experiment) on soil $\mathrm{CO}_{2}$ efflux and found out that soil respiration was significantly reduced. Sulzman et al. (2005) studied the contribution of litter to total soil $\mathrm{CO}_{2}$ efflux in an old growth coniferous forest and found that measured fluxes from plots with doubled needle litter led to an additional flux. Metcalfe et al. (2007) investigated factors controlling spatio-temporal variation in $\mathrm{CO}_{2}$ efflux from surface litter at four rain forest sites in the eastern Amazon. They found that litter contribution showed no clear seasonal change, though experimental precipitation exclusion was associated with a 10 -fold reduction in litter respiration relative to unmodified sites. These findings invite more attention and studies on how litter controls $\mathrm{CO}_{2}$ efflux.

Table 4 shows Pearson correlations between the sitespecific factors (cluster constant, root biomass factor, litter layer factor, organic matter factor). These correlations are overall insignificant, ensuring that the evaluated nonlinear model is not over-parameterized.

\section{3 $\mathrm{CO}_{2}$ production and transport through soil layers}

As mentioned in Sect. 2, soil hydraulic parameters were derived from soil moisture measurements using inverse solutions through the HYDRUS-1D model system. The calibrated hydraulic parameters were first combined with soil temperature measurements to adjust heat transport parameters. All these parameters were finally used to simulate soil $\mathrm{CO}_{2}$ efflux for one site picked from each cluster presented in the previous sub-sections.

Figure 5 shows observations versus best simulations with the associated uncertainty ranges for the soil $\mathrm{CO}_{2}$ efflux of the measurement sites picked up from the clusters. The table associated with Fig. 5 provides the quality measure of the simulation for the different sites taken from the clusters. The quality measures are just acceptable. The coefficient of determination $\left(R^{2}\right)$, the model efficiency (ME) and the index of agreement (IA) range from 0.26 to 0.86 . The percentage of measurements captured by $95 \%$ prediction uncertainty ranges from 71 to $88 \%$, while the uncertainty bands are relatively large (from 1.32 to 2.72 ).

Overall, the uncertainty of the simulations using the HYDRUS-1D model were relatively high compared to those of the estimations presented in Sect. 3.2, where combined effects of soil moisture and soil temperature were directly used as a time-dependent rating factor for site-specific $\mathrm{CO}_{2}$ production and transport.

Table 5 shows calibrated values for site-specific $\mathrm{CO}_{2}$ production and transport parameters such as the molecular diffusion coefficient of carbon dioxide in air, the molecular diffusion coefficient of carbon dioxide in water, the optimal $\mathrm{CO}_{2}$ production by soil microorganisms for the entire soil profile and the optimal $\mathrm{CO}_{2}$ production by plant roots for the entire soil profile. These values might be seen as characteristic values for both the investigated sites and the underlying clusters. The lowest respiration is observed for Cluster $\mathrm{C} 4$ and can be explained by the permanent moisture condition, which inhibits microbial activity. The highest respiration rates are observed at Cluster $\mathrm{C} 3$, which may be seen as a predominant effect, non-extreme/intermediary and suitable soil moisture condition resulting in optimal conditions for microorganism. It should be mentioned that Cluster C3 was identified in Sect. 3.2 as under moderate influence of the 

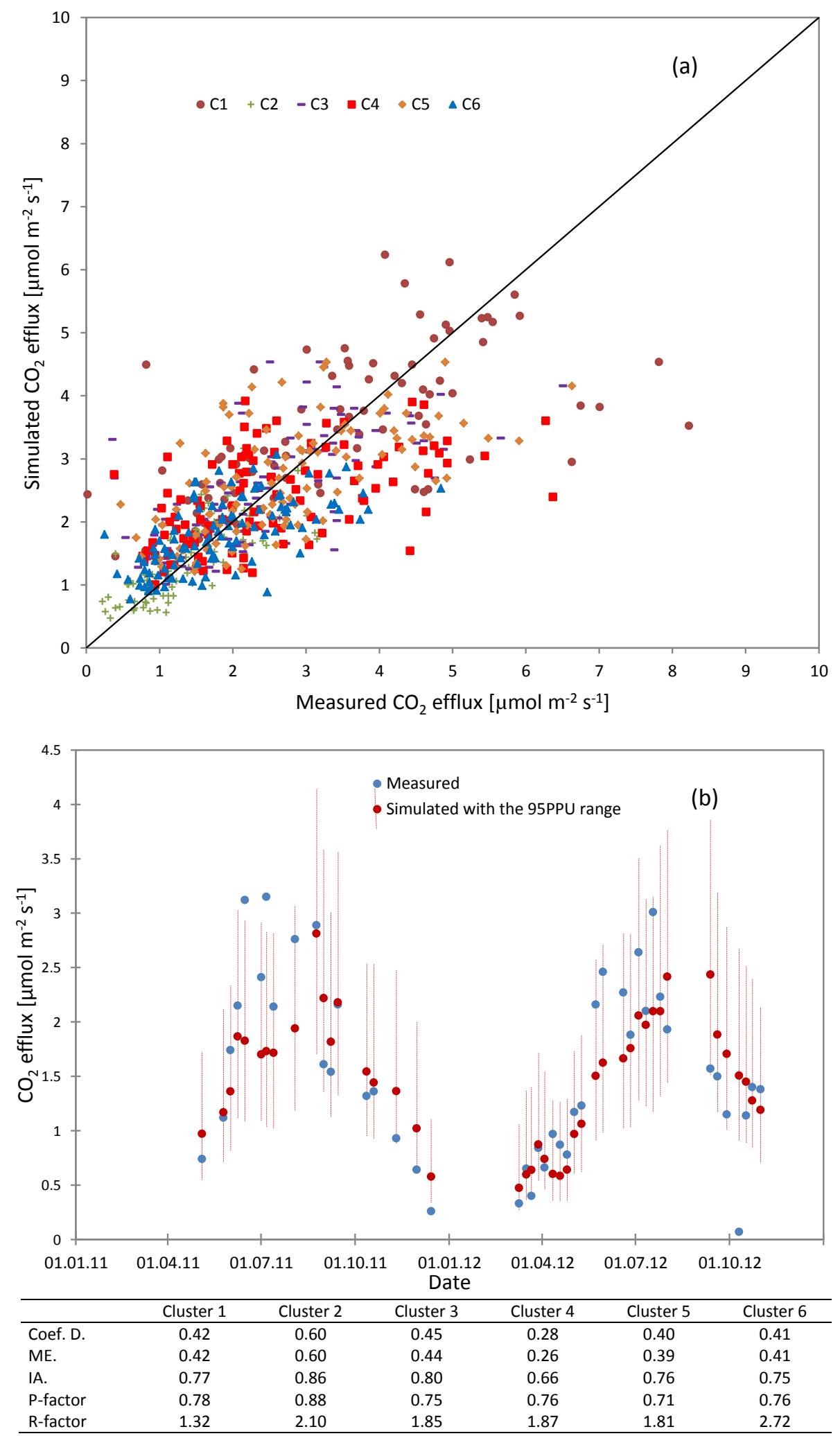

Figure 5. Simulated vs. observed $\mathrm{CO}_{2}$ efflux for selected sites from the clusters using HYDRUS-1D. The simulation quality measures are displayed in the associated table. (a) Scatter plot of simulated vs. measured $\mathrm{CO}_{2}$ efflux for all clusters from 2006 to 2012 , (b) simulated vs. measured $\mathrm{CO}_{2}$ efflux with associated 95 percent prediction uncertainty (95 PPU) from 2011 to 2012 for the site M8 (cluster C2). C1...6 means clusters 1 ...6. 
Table 4. Pearson correlations between parameters of the modified Fang et al. (1998) model (Eq. 4). Correlations are underlined while values in italic are the significance of the correlations under alpha $=0.05$. Values in bold highlight correlations with significance $<0.05$.

\begin{tabular}{lrrrrrrr}
\hline Variables & $k_{0}$ & $\Delta E$ & $\alpha$ & $a$ & $b$ & $c$ & $d$ \\
\hline$k_{0}$ & & $\mathbf{0 . 9 8 2}$ & -0.241 & $\mathbf{0 . 9 7 6}$ & -0.023 & $\mathbf{0 . 9 8 0}$ & -0.042 \\
$\Delta E$ & $\underline{\mathbf{0 . 9 8 2}}$ & & -0.330 & $\mathbf{0 . 9 7 5}$ & -0.078 & $\mathbf{0 . 9 7 7}$ & -0.102 \\
$\alpha$ & $\underline{-0.241}$ & $\frac{-0.330}{\mathbf{0 . 9 7 6}}$ & & -0.211 & -0.203 & -0.219 & -0.212 \\
$a$ & $\underline{\mathbf{0 . 9 7 5}}$ & $\underline{-0.211}$ & & -0.238 & $\mathbf{0 . 9 9 9}$ & -0.256 \\
$b$ & $\underline{-0.023}$ & $\frac{-0.078}{-0.203}$ & $\underline{-0.238}$ & & -0.220 & $\mathbf{0 . 9 9 8}$ \\
$c$ & $\underline{\mathbf{0 . 9 8 0}}$ & $\underline{\underline{\mathbf{0 . 9 7 7}}}$ & $\underline{-0.219}$ & $\underline{\mathbf{0 . 9 9 9}}$ & $\underline{-0.220}$ & & -0.238 \\
$d$ & $\underline{-0.042}$ & $\underline{-0.102}$ & $\underline{-0.212}$ & $\underline{-0.256}$ & $\underline{\mathbf{0 . 9 9 8}}$ & $\underline{-0.238}$ & \\
\hline
\end{tabular}

Table 5. Estimated parameters of the HYDRUS-1D model: Air Diff. $=$ Molecular diffusion coefficient of carbon dioxide in air $\left(\mathrm{mm}^{-2} \mathrm{~d}^{-1}\right)$; Water Diff. $=$ Molecular diffusion coefficient of carbon dioxide in water $\left(\mathrm{mm}^{-2} \mathrm{~d}^{-1}\right)$; OCDP microorganisms $=\mathrm{Optimal} \mathrm{CO}_{2}$ production by soil microorganisms for the entire soil profile $\left(\mu \mathrm{mol} \mathrm{m} \mathrm{m}^{-2} \mathrm{~s}^{-1}\right)$; OCDP roots $=$ Optimal $\mathrm{CO}_{2}$ production by plant roots for the entire soil profile $\left(\mu \mathrm{mol} \mathrm{m} \mathrm{m}^{-2} \mathrm{~s}^{-1}\right)$.

\begin{tabular}{lrrrrrr}
\hline & M1 (C1) & M8 (C2) & WA1 (C3) & WA7 (C4) & WA10 (C5) & WA11 (C6) \\
\hline Air Diff. & 1373760 & 1373760 & 1373760 & 1373760 & 1373760 & 1373760 \\
Water Diff. & 152.9 & 152.9 & 152.9 & 152.9 & 152.9 & 152.9 \\
OCDP microorganisms & 10.40 & 9.48 & 11.31 & 6.32 & 10.65 & 7.27 \\
OCDP roots & 13.42 & 7.80 & 9.74 & 10.49 & 11.90 & 7.33 \\
\hline
\end{tabular}

time-dependent rating factor (combined effects of soil moisture and soil temperature). The lowest root activities are observed for Cluster C2 (site M8) and Cluster C6 (site WA11) and are partly consistent with conclusions drawn from Fig. 3 in Sect. 3.1, where attention was drawn to a likely inhibiting effect of the litter depth on the $\mathrm{CO}_{2}$ production and transport with a direct link to very low air and heat circulation. This result helps make clear why the activation energy found in Sect. 3.2 (Table 3) is very high. The highest $\mathrm{CO}_{2}$ production from root biomass (Table 5) is shown for Cluster $\mathrm{C} 1$ (site M1) and Cluster C5. This result is also consistent with the efflux gradient shown in Fig. 3 (Sect. 3.1).

\section{Conclusions}

The current work provides a successful extension of earlier relevant research issues (Fang et al., 1998; Richter et al., 1996) by discussing ongoing long-term $\mathrm{CO}_{2}$ efflux measurements and multivariable environmental properties in a western German forest ecosystem.

For the period 2011 to 2012, data from 10 selected measurement sites in the spruce-dominated forest floor of the Wüstebach catchment have shown a spring mean soil $\mathrm{CO}_{2}$ efflux ranging from 1.2 to $3 \mu \mathrm{mol} \mathrm{m}{ }^{-2} \mathrm{~s}^{-1}$ (1.7 to $4.5 \mu \mathrm{mol} \mathrm{m}^{-2} \mathrm{~s}^{-1}$ in summer) associated with a large range of mean volumetric soil moisture ranging from 12 to $33 \%$ ( 8 to $30 \%$ in summer), while the mean soil temperature remains around $8{ }^{\circ} \mathrm{C}\left(12^{\circ} \mathrm{C}\right.$ in summer). This less pronounced seasonal trend hides complex interactions between environmental factors, time-dependent factors and the $\mathrm{CO}_{2}$ efflux rate (Metcalfe et al., 2007).
A multivariate clustering of the measurement sites decreased the complexity level of the environmental control on $\mathrm{CO}_{2}$ efflux and allowed concordant evaluations of a simple nonlinear model of time-dependent rating of site-specific $\mathrm{CO}_{2}$ production compared to simulation issues with the HYDRUS-1D model system. Although the uncertainty increased significantly from the nonlinear time-dependent rating model to the HYDRUS-1D simulations, the comprehensible linkage between the different results and the underlying approaches was not affected.

The results indicate that $\mathrm{CO}_{2}$ efflux from the sub-surface floor of the study area is mainly controlled by soil temperature, moisture condition, root biomass and litter distribution. Four different process-based clusters with very clear physical and bio-chemical conditions (e.g. permanent moisture condition, accumulated litter amount, high changes in the air-filled pores) were found relevant in explaining the spatio-temporal variability of $\mathrm{CO}_{2}$ efflux and providing reference characteristic values for the investigated area. Parameters such as the one describing soil moisture dependency were specified for the clusters, accounting for the link between soil moisture and changes in soil $\mathrm{CO}_{2}$ emission rate. The results provide many other pattern characteristics, such as the optimal $\mathrm{CO}_{2}$ production by soil microorganisms for the entire soil profile and the optimal $\mathrm{CO}_{2}$ production by plant roots for the entire soil profile.

Finally, it should be remembered that the site-specific rating factor approach used in this study produced comprehensible, valid and more certain results compared to using the HYDRUS-1D. 
Acknowledgements. The authors would like to thank the Deutsche Forschungsgemeinschaft (DFG) for financial support of sub-project $\mathrm{C} 1$ of the Transregional Collaborative Research Centre 32 "Patterns in Soil-Vegetation-Atmosphere Systems." Many thanks to all colleagues of the Transregional Collaborative Research Centre 32, especially Dwersteg, who provided data and assistance.

Edited by: P. Stoy

\section{References}

Abbaspour, K. C., Johnson, A., and van Genuchten, M. Th.: Estimating uncertain flow and transport parameters using a sequential uncertainty fitting procedure, Vadose Zone J., 3, 1340-1352, 2004.

AG Bodenkunde: Bodenkundliche Kartieranleitung - BGR u. Geologische Landesämter der Bundesrepublik Deutschland 5th Edition, 438 pp., Hannover, 2005.

Bogena, H. R., Herbst, M., Huisman, J. A., Rosenbaum, U., Weuthen, A., and Vereecken, H.: Potential of wireless sensor networks for measuring soil water content variability, Vadose Zone J., 9, 1-12, doi:10.2136/vzj2009.0173, 2010.

Buchner, J. S., Šimůnek, J., Lee, J., Rolston, D. E., Hopmans, J. W., King, A. P., and Six, J.: Evaluation of $\mathrm{CO}_{2}$ fluxes from an agricultural field using a process-based numerical model, J. Hydrol., 361, 131-143, doi:10.1016/j.jhydrol.2008.07.035, 2008.

Dwersteg, D.: Spatio-temporal patterns of soil $\mathrm{CO}_{2}$-efflux in a forested catchment of the Eifel national park. $\mathrm{PhD}$ thesis, University of Bonn, available at: http://hss.ulb.uni-bonn.de/2012/2823/ 2823.pdf, 2012.

Fang, C. and Moncrieff, J. B.: A model for soil $\mathrm{CO}_{2}$ production and transport 1: Model development, Agr. Forest Meteorol., 95, 225-236, 1999.

Fang, C., Moncrieff, J. B., Gholz, H. L., and Clark, K. C.: Soil $\mathrm{CO}_{2}$ efflux and its spatial variation in a Florida slash pine plantation, Plant Soil, 205, 135-146, 1998.

Feddes, R. A., Kowalik, P. J., and Zaradny, H.: Simulation of Field Water Use and Crop Yield, John Wiley \& Sons, New York, NY, 1978.

Fiener, P., Dlugoß, V., Korres, W., and Schneider, K.: Spatial variability of soil respiration in a small agricultural watershed - Are patterns of soil redistribution important?, Catena, 94, 3-16, 2011.

Hashimoto, T., Miura, S., and Ishizuka, S.: Temperature controls temporal variation in soil $\mathrm{CO}_{2}$ efflux in a secondary beech forest in Appi Highlands, Jpn. J. Forest Res., 14, 44-50, 2009.

Howard, P. J. A. and Howard, D. M.: Respiration of decomposing litter in relation to temperature and moisture. Microbial decomposition of tree and shrub leaf litter, Oikos, 33, 457-465, 1979.

Hui, D. and Luo, Y.: Evaluation of soil $\mathrm{CO}_{2}$ production and transport in Duke Forest using a process-based modeling approach, Global Biogeochem. Cy., 18, GB4029, doi:10.1029/2004GB002297, 2004.

Jassal, R., Black, A., Novak, M., Morgenstern, K., Nesic, Z., and Gaumont-Guay, D.: Relationship between soil $\mathrm{CO}_{2}$ concentrations and forest-floor $\mathrm{CO}_{2}$ effluxes, Agr. Forest Meteorol., 130, 176-192, 2005.

Jenkinson, D. S., Adams, D. E., and Wild, A.: Model estimates of $\mathrm{CO}_{2}$ emissions from soil in response to global warming, Nature, 351, 304-306, 1991.
Joffre, R., Ourcival, J., Rambal, S., and Rocheteau, A.: The key-role of topsoil moisture on $\mathrm{CO}_{2}$ efflux from a Mediterranean Quercus ilex forest, Ann. For. Sci., 60, 519-526, 2003.

Kang, S., Doh, S., and and Lee, D.: Topographic and climatic controls on soil respiration in six temperate mixedhardwood forest slopes, Korea, Glob. Change Biol., 9, 14271437, doi:10.1046/j.1365-2486.2003.00668.x, 2003.

Li, Y., Xu, M., Sun, O. J., and Cui, W.: Effects of root and litter exclusion on soil $\mathrm{CO}_{2}$ efflux and microbial biomass in wet tropical forests, Soil Biol. Biochem., 36, 2111-2114, 2004.

Longdoz, B., Yernaux, M., and Aubinet, M.: Soil $\mathrm{CO}_{2}$ efflux measurements in a mixed forest: impact of chamber disturbances, spatial variability and seasonal evolution, Glob. Change Biol., 6, 907-917, 2000.

McKay, M. D., Beckman, R. J., and Conover, W. J.: A comparison of three methods for selecting values of input variables in the analysis of output from a computer code, Technometrics, 21, 239-245, 1979.

Metcalfe, D. B., Meir, P., Aragao, L. E. O. C., Malhi, Y., da Costa, A. C. L., Braga, A., Goncalves, P. H. L., de Athaydes, J., de Almeida, S. S., and Williams, M.: Factors controlling spatio-temporal variation in carbon dioxide efflux from surface litter, roots, and soil organic matter at four rain forest sites in the eastern Amazon, J. Geophys. Res., 112, G04001, doi:10.1029/2007JG000443, 2007.

Moncrieff, J. B. and Fang, C.: A model for soil $\mathrm{CO}_{2}$ production and transport 2: Application to a Forida Pinus elliotte plantation, Agr. Forest Meteorol., 95, 237-256, 1999.

Morales, P., Sykes, M. T., Prentice, I. C., Smith, P., Smith, B., Bugmann, H., Zierl, B., Friedlingstein, P., Viovy, N., Sabate, S., Sanchez, A., Pla, E., Gracia, C. A., Sitch, S., Arneth, A., and Ogee, J.: Comparing and evaluating process-based ecosystem model predictions of carbon and water fluxes in major European forest biomes, Glob. Change Biol., 11, 2211-2233, doi:10.1111/j.1365-2486.2005.01036.x, 2005.

Nash, J. E. and Sutcliffe, J. V.: River flow forecasting through conceptual models - Part I - A discussion of principles, J. Hydrol., 10, 282-290, 1970.

Niinistö, S. M., Kellomäki, S., and Silvola, J.: Seasonality in a boreal forest ecosystem affects the use of soil temperature and moisture as predictors of soil $\mathrm{CO}_{2}$ efflux, Biogeosciences, 8, 3169-3186, doi:10.5194/bg-8-3169-2011, 2011.

Pacific, V. J., McGlynn, B. L., Riveros-Iregui, D. A., Epstein, H. E., and Welsch, D. L.: Differential soil respiration responses to changing hydrologic regimes, Water Resour. Res., 45, W07201, doi:10.1029/2009WR007721, 2009.

Pandey, R. R., Sharma, G., Singh, T. B., and Tripathi, S. K.: Factors influencing soil $\mathrm{CO}_{2}$ efflux in a northeastern Indian oak forest and plantation, Afr. J. Plant Sci., 4, 280-289, 2010.

Patwardhan, A. S., Nieber, J. L., and Moore, I. D.: Oxygen, carbon dioxide, and water transfer in soils: mechanism and crop response, Trans. ASEA, 31, 1383-1395, 1988.

Pumpanen, J., Ilvesniemi, H., and Hari, P.: A Process-Based Model for Predicting Soil Carbon Dioxide Efflux and Concentration, Soil Sci. Soc. Am. J., 67, 402-413, 2003.

Raich, J. W. and Schlesinger, W. H.: The global carbon dioxide flux in soil respiration and its relationship to vegetation and climate, Tellus B, 44, 81-99, 1992. 
Reichstein, M., Rey, A., Freibauer, A., Tenhunen, J., Valentini, R., Banza, J., Casals, P., Cheng, Y., Gru, J. M., Irvine, J., Joffre, R., Law, B. E., Loustau, D., Miglietta, F., Oechel, W., Ourcival, J., Pereira, J. S., Peressotti, A., Ponti, F., Qi, Y., Rambal, S., Rayment, M., Romanya, J., and Rossi, F.: Modeling temporal and large-scale spatial variability of soil respiration from soil water availability, temperature and vegetation productivity indices, Global Biogeochem. Cy., 17, 1104, doi:10.1029/2003GB002035, 2003.

Richter, O., Diekkrüger, B., and Nörtersheuser, P.: Environmental fate modelling of pesticides: from the laboratory to the field scale, Wiley-VCH. S., 281 pp., 1996.

Rosenbaum, U., Bogena, H. R., Herbst, M., Huisman, J. A., Peterson, T. J., Weuthen, A., and Vereecken, H.: Seasonal and event dynamics of spatial soil moisture patterns at the small catchment scale, Water Resour. Res., 48, W10544, doi:10.1029/2011WR011518, 2012.

Saiz, G., Black, K., Reidy, B., Lopez, S., and Farrell, E. P.: Assessment of soil $\mathrm{CO}_{2}$ efflux and its components using a processbased model in a young temperate forest site, Geoderma, 139, 79-89, doi:10.1016/j.geoderma.2006.12.005, 2007.

Schlesinger, W. H.: Carbon balance in terrestrial detritus, Annu. Rev. Ecol. Syst., 8, 51-81, 1977.

Sciuto, G. and Diekkrüger, B.: Influence of soil heterogeneity and spatial discretization on water balance modelling in a headwater forest catchment, Vadose Zone J., 9, 955-969, doi:10.2136/vzj2009.0166, 2010.

Shi, P., Zhang, X., Zhong, Z., and Ouyang, H.: Diurnal and seasonal variability of soil $\mathrm{CO}_{2}$ efflux in a cropland ecosystem on the Tibetan Plateau, Agr. Forest Meteorol., 137, 220-233, 2006.

Shibistova, O., LIoyd, J., Evgravova, S., Savushkina, N., Zrazhevskaya, G., Arneth, A., Knohl, A., Kolle, O., and Schulze, E. D.: Seasonal and spatial variability in soil $\mathrm{CO}_{2}$ efflux rates for a central Siberian Pinus sylvestris forest, Tellus B, 54, 552-567, 2002.
Šimůnek, J. and Suarez, D. L.: Modeling of carbon dioxide transport and production in soil: 1. Model development, Water Resour. Res., 29, 487-497, 1993a.

Šimůnek, J. and Suarez, D. L.: The SOILCO2 code for simulating one-dimensional carbon dioxide production and transport in variably saturated porous media, Version 1.1, Research Report No. 127, U.S. Salinity Laboratory, USDA,ARS, Riverside, California, 1993b.

Šimůnek, J., van Genuchten, M. Th., and Šejna, M.: The HYDRUS1D software package for simulating the one-dimensional movement of water, heat, and multiple solutes in variably-saturated media, Version 3.0, HYDRUS Software Series 1, Department of Environmental Sciences, University of California Riverside, Riverside, CA, 270 pp., 2005.

Sokal, R. R. and Rohlf, F. J.: Biometry: The Principles and Practice of statistics in Biological Research, 3rd ed., W H Freeman and Company, New York, 634-654, 1995.

Sulzman, E. W., Brant, J. B., Bowden, R. D., and Lajtha, K.: Contribution of aboveground litter, belowground litter, and rhizosphere respiration to total soil $\mathrm{CO}_{2}$ efflux in an old growth coniferous forest, Biogeochemistry, 73, 231-256, 2005.

Walker, A. and Allen, R.: Influence of soil and environmental factors on pesticide persistence, Symposium on soils and crop protection chemicals, 21, 89-100, 1984.

Willmott, C. J.: On the validation of models, Phys. Geogr., 2, 184 194, doi:10.1080/02723646.1981.10642213, 1981.

$\mathrm{Xu}, \mathrm{M}$. and Qi, Y.: Soil-surface $\mathrm{CO}_{2}$ efflux and its spatial and temporal variations in a young ponderosa pine plantation in northern California, Glob. Change Biol., 7, 667-677, 2001. 